\title{
A PROTOZOAN PARASITE IN THE SALIVARY GLAND OF THE DOG
}

\author{
LEILA JACKSON
}

From the John McCormick Institute for Infectious Diseases, Chicago

An interesting parasite was found in the salivary glands of two old dogs that were used as controls in the work on rabies. ${ }^{1}$ Nothing is known of the histories of these dogs, and the heads alone were received for examination. The animals were apparently well nourished. The tissues of the neck in both cases were edematous, and in one case the lymph glands were swollen and soft. The salivary glands had a peculiar yellowish color unlike the usual pinkish gray of these glands. In size and consistency they appeared normal.

On examination of the sections certain parts of the glands were found to be heavily infestèd with a peculiar protozoan parasite. In both cases the organisms were most abundant in the small anterior lobe of the submaxillary gland, and in one case they were also present in considerable numbers in the parotid, but in the latter location the forms were less varied.

The parasites are very numerous, many of them of large size and striking in appearance. All the cells of an acinus may contain parasites and a single cell may contain two parasites of different forms. A form which probably represents the vegetative or schizogenous stage consists of a deeply stained circular, central portion of variable size surrounded by a clear, radially arranged, unstained zone of varying width. These bodies are usually about 10 mikrons in diameter. The central portion is usually large, about 8 mikrons in diameter, and may be surrounded by a narrow clear zone, but often small, round bodies are seen budding off from the central body or lying free in the peripheral zone. Less frequently there is a small central body, 3-5 mikrons in diameter, with a radially arranged outer zone, sometimes without the small bodies, sometimes filled with the small bodies of quite uniform size and having a rather indefinite radial arrangement. The size of the small bodies seen in parasites with narrow peripheral zones varies considerably. While the majority of these forms are round, some are elongated and more or less irtegular in 
shape. The large parasites fill the cells they inhabit, but the wall of the cell remains, and one usually sees the nucleus of the cells flattened against the wall.

A much smaller and less deeply stained body, which may be an earlier form, is less often seen. In this body the central portion stains deepest, the color shading off toward the periphery without differentiation into central and outer parts.

Another form, which is present in about the same numbers as the first in one dog, and is almost the only form of the organism in the other dog, consists of a clear, lightly blue stained substance in which

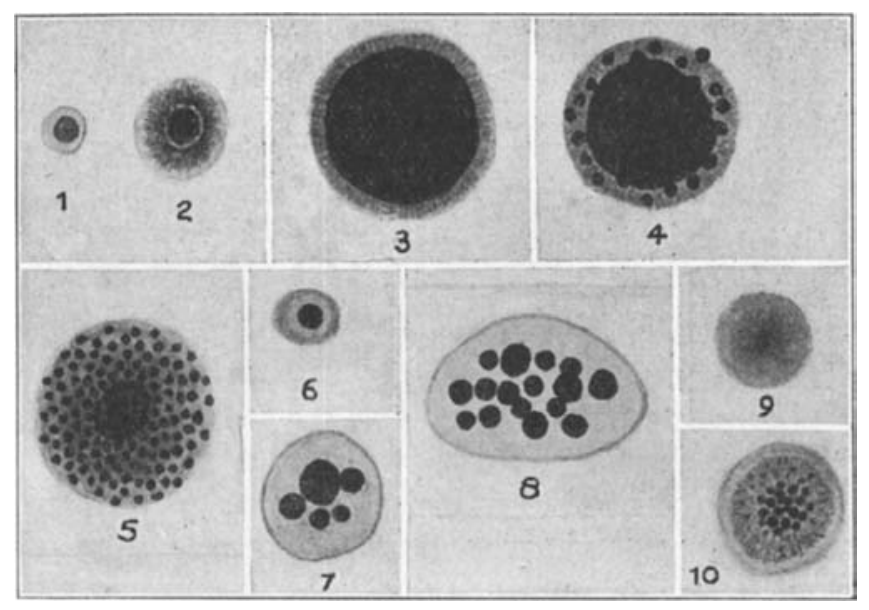

Figs. 1, 2, 3, 4, 5.-Schizogenous forms. Figs. 6, 7, 8.-Sporogenous forms, Fig. 9.Undifferentiated body. Fig. 10.-A body occasionally seen in duct epithelium.

are imbedded one or several round, deeply red stained bodies which differ considerably in size. This cyst-like form varies more in size than the vegetative, being 3 to 10 mikrons in diameter and sometimes of quite irregular shape. The small and medium sized organisms of this type are most numerous. Occasionally one sees a cyst filled with rather small bodies of uniform size. These forms I believe represent the sporogenous stage in the life cycle of the organism.

The vegetative stage of the parasite resembles somewhat that of the organisms found in the ducts of the salivary glands of guinea-pigs ${ }^{2}$ and presumably represents a similar stage in the development of a

- Jour. Infect. Dis., 1920, 26, p. 347. 
related parasite. In these dogs the forms of the organism just described have not been found in the duct epithellium, but occasional cells of the ducts of both the parotid and submaxillary glands of one case present an unusual appearance. Stained with eosin and methyllene blue, these cells take a very deep red stain, have a swollen appearance and stand out distinctly among the less brightly stained normal cells. When examined carefully they are seen to contain many small red bodies, which are brought out distinctly by staining with iron hematoxylin. That these bodies are not secretion granules is evident from the following: They stain strongly with eosin while secretion granules do not; and with iron hematoxylin secretion granules stain more deeply, are smaller and more irregular in shape than these bodies, which are round and quite uniform in size, and the cells containing them desquanate. Rarely an epithelial cell of a duct is seen to contain a large round body with a deeply stained center and radiating peripheral zone, and I have been in doubt as to whether to regard it as a form of the parasite or not.

In the paretid glands of one of the dogs, the acinar cells contain considerable numbers of a smaller, more lightly stained, undifferentiated form. Similar forms occur in small numbers among the first described forms in the submaxillary gland, also in the glands of normal and rabid dogs, and consequently I am undecided whether they are forms of the parasite just described or an entirely different organism.

The lumen of the ducts, especially in infected portions of the submaxillary gland, contain many letkocytes and masses of deeply reddish stained, more or less homogeneous, material and in general have a very much distended appearance. Some of the parasites become detached from the acinar cells and are found lying free in the ducts, but are few in number. The ducts of uninvolved portion of the glands sometimes contain a few small oval ameba-like organisms similar to those so frequently found in the salivary glands of normal and rabid dogs. A peculiar feature of these glands is the comparatively slight reaction of the tissues to the extensive invasion of the parasite. In places in which the organisms are most numerous, there is little if any necrosis, few polymorphonuclear leukocytes in the tissues, and only a moderate amount of infiltration of mononuclear cells, most of which are plasma cells.

This organism apparently belongs among sporozoa since, according to Rivas, ${ }^{3}$ some of the characteristic features of these protozoa are

3 Human Parasitology, 1920, p. 146. 
absence of pseudopodia, reproduction by spore formation, strictly parasitic nature requiring elaborated or predigested food for their nourishment, a simple structure consisting of cytoplasm and nucleus and a rather complicated life cycle. It seems probable that further classification would place them in class Telosporidia, group 2, Coccidia and family 4, Polysporcystidae. 